\title{
Estudo florístico de plantas vasculares associadas às áreas úmidas na Cadeia do Espinhaço (MG), Brasil ${ }^{1}$
}

\author{
SYLVIA THERESE MEYER ${ }^{2,4}$ e EDIVANI VILLARON FRANCESCHINELLI ${ }^{3}$
}

(recebido: 20 de maio de 2009; aceito: 22 de outubro de 2010)

\begin{abstract}
Floristic study of vascular plants associated with wetlands in the Espinhaço Range, Minas Gerais State, Brazil). The Espinhaço Range in the Minas Gerais State comprises a group of mountains that ranges between the limits of $20^{\circ} 21^{\prime} 56^{\prime \prime} \mathrm{S}$

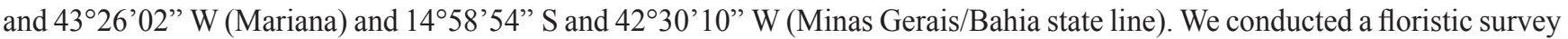
of vascular plant species associated with wetlands in ten areas, using a $5 \times 50 \mathrm{~m}$ transect in each area. Fifty three families, 126 genera and 224 species were represented. Families with highest species richness were: Cyperaceae (17.86\%), Poaceae (10.27\%), Asteraceae (7.14\%) Eriocaulaceae (4.91\%), and Melastomataceae (4.91\%). Cluster analysis showed higher similarity between environments of rivers and lakes geographically closer, but the Mantel test for all areas was not significant $(P=0.17)$. The large number of unique species influenced the high value of the estimator "Jacknife" (341.9). The São Francisco River basin was the richest in species number (116). Environments sampled showed different plant communities, which reflect their floristic peculiarities.
\end{abstract}

Key words - aquatic macrophytes, floristic, wetlands

RESUMO - (Estudo florístico de plantas vasculares associadas às áreas úmidas na Cadeia do Espinhaço, MG). A Cadeia do Espinhaço no Estado de Minas Gerais compreende um grupo de serras entre os limites 20²1'56" S e 4326'02” W (Mariana) e 1458'54" S e 42³0'10" W (Divisa Minas Gerais/Bahia). Foi realizado um levantamento florístico das espécies vasculares associadas a áreas úmidas em dez áreas, utilizando-se um transecto de $5 \times 50 \mathrm{~m}$, em cada área. Foram representadas 53 famílias, 126 gêneros e 224 espécies. As famílias com maior riqueza específica foram Cyperaceae (17,86\%), Poaceae (10,27\%), Asteraceae $(7,14 \%)$, Eriocaulaceae (4,91\%) e Melastomataceae (4,91\%). A análise de agrupamento apresentou maior similaridade entre ambientes de rios e lagoas geograficamente mais próximas, porém o resultado do teste de Mantel para o conjunto das áreas não foi significativo $(P=0,17)$. O grande número de espécies únicas influenciou o valor elevado do estimador “Jacknife” (341,9). A insuficiência amostral indicada relaciona-se, principalmente, à grande abrangência geográfica e a heterogeneidade dos ambientes amostrados. A Bacia do Rio São Francisco apresentou a maior riqueza em número de espécies (116). Nos ambientes amostrados na Cadeia do Espinhaço, foram verificadas comunidades vegetais que refletem diferentes peculiaridades florísticas.

Palavras-chave - áreas úmidas, florística, macrófitas aquáticas

\section{Introdução}

O Estado de Minas Gerais possui uma área de $587.172 \mathrm{~km}^{2}$ e apresenta grande variação de formas de relevo, clima, solos e rede hidrográfica extremamente rica, abrigando 14 bacias hidrográficas. Aproximadamente 90\% do seu território é drenado por cinco grandes bacias: Rio São Francisco, Rio Grande, Rio Paranaíba, Rio Doce e Rio Jequitinhonha (Costa et al. 1998). A Bacia do Rio São Francisco é a maior delas e drena cerca de $40 \%$ do território mineiro, tendo extensão total de $1.135 \mathrm{~km}$

1. Parte da tese de Doutorado do primeiro autor, Programa de Pós Graduação em Biologia Vegetal do Departamento de Botânica da Universidade Federal de Minas Gerais, MG, Brasil.

2. Fundação Centro Tecnológico de Minas Gerais (Cetec), Av. José Cândido da Silveira, 2000, Bairro Horto, 31.170-000 Belo Horizonte, MG, Brasil.

3. Universidade Federal de Goiás, Departamento Biologia Geral - ICB, Campus Samambaia. 74690-900 Goiânia, GO, Brasil.

4. Autor para correspondência: sylvia.meyer@cetec.br dentro do Estado de Minas Gerais (Cetec 1983). A Bacia do Rio Grande drena 15\% do estado, a do Rio Doce e Paranaíba $12 \%$ cada uma e a do Rio Jequitinhonha drena 11\% (Costa et al. 1998).

Em função da grande variação dos componentes abióticos, as áreas úmidas existentes no estado também apresentam grande heterogeneidade de ecossistemas. Os ambientes lóticos podem apresentar diversos habitats como trechos encachoeirados, corredeiras, remansos e poços e, os ecossistemas lênticos, representados por lagoas de diversas origens, açudes e reservatórios, constituem importantes locais para a colonização de plantas aquáticas. As lagoas marginais aos rios são um tipo muito freqüente de ecossistema lêntico constantes na bacia do Rio São Francisco.

As áreas úmidas mineiras foram indicadas como prioritárias para a implementação de programas de manejo e conservação segundo o "Atlas - Biodiversidade em Minas Gerais", elaborado a partir do "Workshop" promovido pela Fundação Biodiversitas (Costa et al. 
1998). Neste documento foi estabelecida a Cadeia do Espinhaço como uma região prioritária para o desenvolvimento de estudos voltados à conservação da biodiversidade em Minas Gerais.

A região da Cadeia do Espinhaço, cenário histórico de inúmeros estudos botânicos, é destacada por sua riqueza florística e pela ocorrência de muitas espécies endêmicas. Entretanto, ainda são incipientes os levantamentos florísticos em ambientes úmidos desta Cadeia. Além disso, a crescente destruição de seus habitats, a introdução de espécies exóticas pelo aquarismo, piscicultura, jardinagem e outras atividades antrópicas têm causado efeitos negativos grandes sobre a biodiversidade destes ambientes úmidos.

Em face do exposto, o objetivo principal deste estudo foi o levantamento florístico das plantas vasculares ocorrentes em áreas úmidas da região da Cadeia do Espinhaço nos limites do Estado de Minas Gerais. A incorporação de tais estudos irá suprir algumas das lacunas apontadas e subsidiar estratégias para conservação das áreas úmidas e da biodiversidade vegetal em Minas Gerais.

\section{Material e métodos}

A Cadeia do Espinhaço, em Minas Gerais, compreende um grupo de serras entre os limites $20^{\circ} 21^{\prime} 56^{\prime \prime} \mathrm{S}-43^{\circ} 26^{\prime} 02^{\prime \prime} \mathrm{W}$ (Mariana) e 145' $54^{\prime \prime}$ S-42 $30^{\prime} 10^{\prime \prime} \mathrm{W}$ Gr. (Divisa Minas Gerais/Bahia). Essa unidade geomorfológica, localizada no centro norte de Minas Gerais, possui um desenvolvimento longitudinal, com seu limite sul no Quadrilátero Ferrífero e o limite norte ultrapassando a divisa do Estado e prolongando-se pelo interior da Bahia (Cetec 1983). A Cadeia do Espinhaço constitui o grande divisor de águas entre as drenagens das bacias do Rio São Francisco, a oeste, e do Rio Doce, Rio Jequitinhonha e outras menores a leste.

O relevo apresenta-se dividido em dois grandes conjuntos dentro de Minas Gerais. Um localizado ao sul da Cadeia e caracterizado por superfícies aplainadas e/ou onduladas intercaladas com cristas e picos. Outra porção inicia-se na altura do Município de Diamantina e apresenta predominantemente trechos de cristas e picos e superfícies aplainadas e/ou onduladas (Joly 1970). Apesar de situar-se em latitudes tropicais, a Cadeia do Espinhaço apresenta clima do tipo tropical de altitude (Nimer 1977), caracterizado por invernos secos e verões brandos e chuvosos, com temperaturas médias abaixo de $22{ }^{\circ} \mathrm{C}$. As médias anuais de precipitação para a região da Cadeia do Espinhaço sofrem variações entre trechos. A precipitação média anual varia do Quadrilátero Ferrífero até Diamantina entre 1.400 a $1.450 \mathrm{~mm}$, no trecho de Diamantina até Grão Mogol varia entre 1.000 a $1.400 \mathrm{~mm}$ e de Grão Mogol para o norte do Estado a precipitação média anual varia entre 800 a $1.000 \mathrm{~mm}$. O período úmido corresponde de 7 a 8 meses e o período seco de 3 a 4 meses, que coincide com o inverno.

Em termos fitogeográficos a região da Cadeia do Espinhaço localiza-se entre os Domínios da Mata Atlântica e do Cerrado (Rizzini 1997). O tipo vegetacional predominante na região é o campo rupestre. Essa vegetação é um tipo fitofisionômico predominantemente herbáceo-arbustivo, com a presença eventual de arvoretas pouco desenvolvidas até dois metros de altura, ocorrendo geralmente em solos litólicos ou nas frestas dos afloramentos (Ribeiro \& Walter 1998).

As áreas amostrais foram inicialmente pré estabelecidas tomando-se por referência as Cartas do Brasil (IBGE 1977) nas escalas 1:50.000 e 1:100.000 da região da Cadeia do Espinhaço, dentro dos limites do Estado de Minas Gerais. As áreas de amostragem foram definidas considerando-se critérios como: 1) ambientes bem conservados;2) a ocorrência de comunidades de plantas associadas a ambientes úmidos; 3) bacias hidrográficas distintas - a fim de se obter melhor distribuição da diversidade ao longo da Cadeia do Espinhaço. Dessa forma, foram selecionadas dez áreas, sendo o limite sul localizado no Município de Mariana e o limite norte no Município de Riacho dos Machados (figura 1, tabela 1). As áreas foram assim denominadas: Lagoa Tanque da Fazenda - TANQ (1), Lagoa Nascentes do Taboão - NASC (2), Lagoa Comprida - COMPR (3), Lagoa Terra de Arroz - TERR (4), Lagoa Arame - ARAM (5), Rio Corrento - CORR (6), Rio Taquaral - TAQU (7), Lagoa Americana - AMER (8), Rio Preto - PRET (9), Lagoa Estivinha - ESTI (10).

A comunidade estudada foi denominada como o conjunto de plantas vasculares, arbustivas e herbáceas, associadas a ambientes úmidos. Para o desenvolvimento deste estudo, optou-se em não adotar a terminologia macrófitas aquáticas para as espécies amostradas. Apesar da maioria se enquadrar nesta categoria, algumas espécies amostradas não puderem ser claramente incluídas no conceito de macrófitas aquáticas, umas por serem ocasionalmente aquáticas e outras por falta de informações sobre a sua dependência da água. Não foram consideradas neste estudo as espécies arbóreas das florestas ciliares, apesar de algumas vezes ocorrerem dentro da área amostral. O levantamento florístico foi realizado durante dois anos, com sete campanhas de amostragem, abrangendo períodos de seca nos meses de setembro/2001, agosto/2002, maio e julho/2003 e períodos de chuva em dezembro/2001, março e dezembro/2002. Em cada área selecionada foram coletados todos os indivíduos ao longo de um transecto de $50 \times 5 \mathrm{~m}$ (Mueller-Dombois \& Ellenberg 1974, Haslam 1978), orientado paralelamente em seu maior comprimento à linha de margem, de maneira que 2,5 metros estendiam-se às margens das áreas úmidas e 2,5 metros na lâmina de água. $\mathrm{O}$ material botânico coletado foi herborizado conforme as técnicas usuais de herbário e identificado taxonomicamente. Após identificação, foi incorporado ao Herbário e Xiloteca da Fundação Centro Tecnológico de Minas Gerais (HXBH).

A lista florística das dez áreas de amostragem foi organizada segundo APG II (2003), por ordem alfabética de famílias, gêneros e espécies. A partir destes dados, construiu-se 

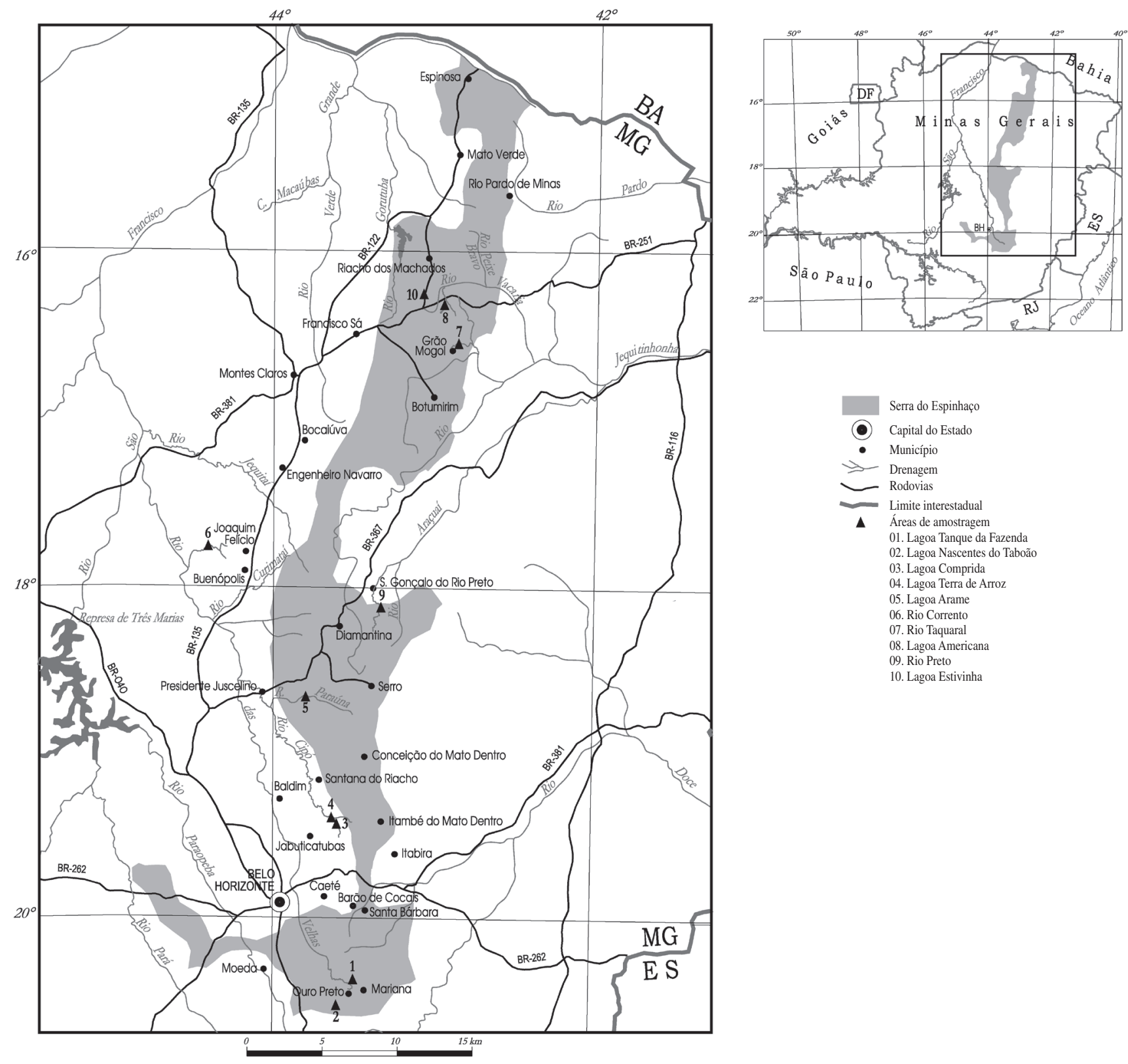

Figura 1. Mapa de localização das áreas de amostragem das plantas vasculares associadas a áreas úmidas na Cadeia do Espinhaço (Minas Gerais, Brasil).

Figure 1. Location map of the sampled areas of vascular plants associated with wetlands in the Espinhaço Range (Minas Gerais State, Brazil).

uma matriz binária de presença e ausência para a estimativa da riqueza e a análise aglomerativa. Nessas análises, utilizouse o programa BioDiversity Professional. O dendrograma foi construído utilizando-se o índice de similaridade de Jaccard e a média de grupo (UPGMA).

Foi utilizado o estimador Jackknife de primeira ordem (Heltshe \& Forrester 1983), para estimar a riqueza de espécies em toda a região, diversidade gama, segundo a equação:

$$
S_{\text {jack } 1}=S_{\text {obs }}+Q_{1}(m-1 / m)
$$

onde, " $S_{\text {obs }}$ " é o número total de espécies observado, " $Q_{1}$ " é o número de espécies encontrado em apenas uma área (espécies únicas) e "m" o número total de áreas.

Foram testadas a significância das diferenças de similaridade florística e distância geográfica entre as áreas por meio do teste de Mantel, utilizando-se o programa FSTAT (Goudet 2002), com 20.000 permutações ao acaso. A primeira matriz foi elaborada com os dados de similaridade de Jaccard e a segunda matriz foi composta pelas distâncias geográficas em quilômetros, em linha reta, entre as áreas de amostragem. 


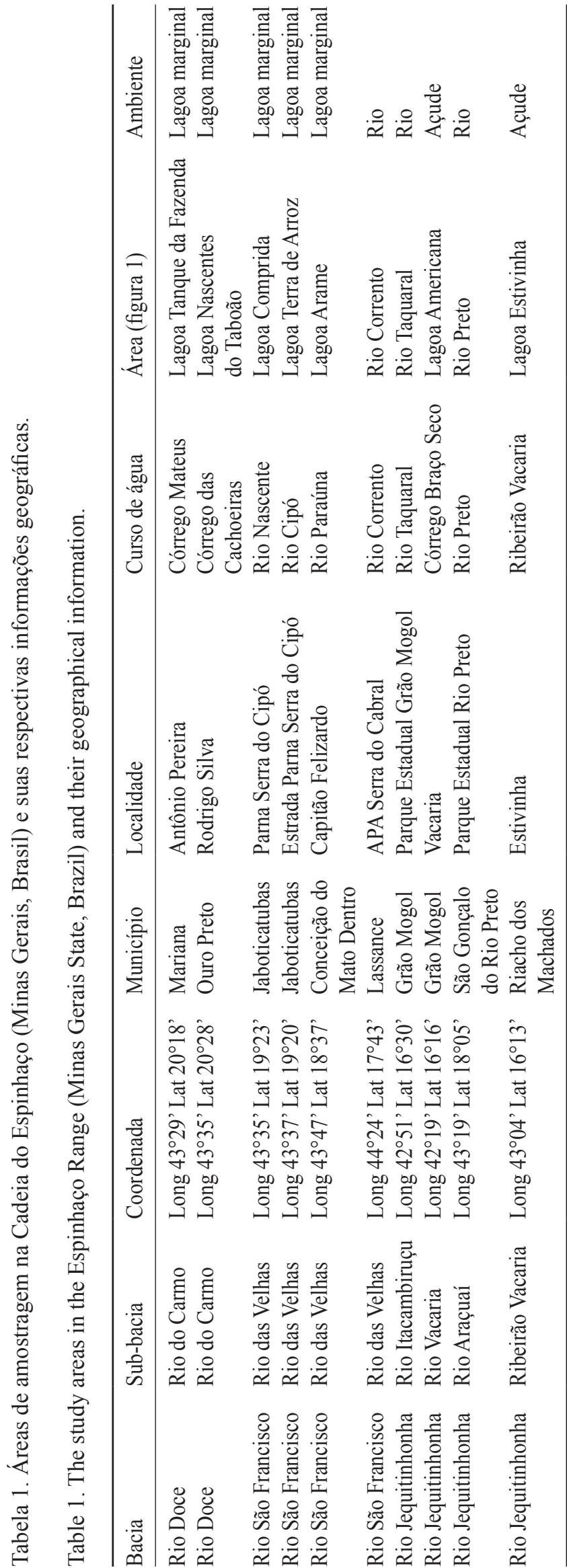

Utilizou-se o mapa digitalizado e o Programa Autocad para medir as distâncias geográficas. Os índices de similaridade de Jaccard entre as áreas foram calculados no programa BioDap (Magurran 1988).

Foram consideradas espécies invasoras as plantas que têm a capacidade de se proliferar e dispersar mantendo uma população viável ao longo do tempo, podem ser tanto exóticas como alóctones, ou seja, aquelas provenientes de outro país e as deslocadas da sua zona geográfica nativa, dentro do mesmo país (Espínola \& Júlio Junior 2007). As espécies indicadas como invasoras, no presente estudo, foram as citadas por Leitão Filho et al. (1972; 1975), Bacchi et al. (1984), Brandão et al. (1989) e Lorenzi (2000).

\section{Resultados}

Foram coletados 824 exemplares pertencentes a 53 famílias, 126 gêneros e 224 espécies (tabela 2). As Pteridófitas foram representadas por seis espécies de quatro famílias e as Angiospermas apresentaram 109 espécies em 49 famílias. As famílias de maior riqueza específica foram Cyperaceae (17,86\%), Poaceae (10,27\%), Asteraceae (7,14\%), Eriocaulaceae (4,91\%) e Melastomataceae (4,91\%). Dez famílias representam aproximadamente $62 \%$ das espécies. Os gêneros com maior número de espécies foram: Eleocharis (12), Cyperus (11), Rhynchospora (8), Ludwigia (8), Panicum (8), Utricularia (7) e Xyris (7). Foram nove as espécies de maior freqüência nas áreas, sendo Cyperus haspan. a mais freqüente, ocorrendo em sete áreas. Rhynchospora corymbosa, Utricularia gibba, Mayaca fluviatilis e Xyris laxifolia foram registradas em seis áreas e Ludwigia nervosa, Nymphoides indica, Eleocharis sellowiana e Polygonum meissnerianum, foram amostradas em cinco áreas. Sete espécies são citadas como endêmicas ao Estado de Minas Gerais (tabela 2).

Foram registradas 131 espécies que ocorreram em apenas uma área e 42 que tiveram duas ocorrências. Estes registros somados correspondem a aproximadamente $77 \%$ do total de espécies amostradas. O estimador de riqueza Jackknife (estimador de primeira ordem), foi superior ao número de espécies observado e correspondeu a 341,9 .

As áreas inclusas na bacia do Rio São Francisco apresentaram a maior riqueza de espécies (116), seguida pelas áreas das bacias do Jequitinhonha (104) e Doce (101). Algumas espécies foram amostradas somente em determinadas bacias, podendo ser citadas as seguintes: Burmannia bicolor, Burmannia capitata, Genlisea pygmaea e Diamantina lombardii para a bacia do Jequitinhonha; Leiothrix flavescens, Utricularia praelonga, Habenaria parviflora e Oncidium 
Tabela 2. Famílias e espécies de plantas vasculares associadas às áreas úmidas, na Cadeia do Espinhaço (Minas Gerais, Brasil), com suas respectivas áreas de ocorrência. (1 = Lagoa Tanque da Fazenda; 2 = Lagoa Nascentes do Taboão; 3 = Lagoa Comprida; 4 = Lagoa Terra de Arroz; 5 = Lagoa Arame; 6 = Rio Corrento; 7 = Rio Taquaral; $8=$ Lagoa Americana; $9=$ Rio Preto; 10 = Lagoa Estivinha).

Table 2. Families and species of vascular plants associated with wetlands in the Espinhaço Range (Minas Gerais State, Brazil), with their respective areas of occurrence. ( 1 = Lagoa Tanque da Fazenda; 2 = Lagoa Nascentes do Taboão; 3 = Lagoa Comprida; 4 = Lagoa Terra de Arroz; 5 = Lagoa Arame; 6 = Rio Corrento; 7 = Rio Taquaral; 8 = Lagoa Americana; 9 = Rio Preto; $10=$ Lagoa Estivinha).

\begin{tabular}{|c|c|c|c|c|c|c|c|c|c|c|c|}
\hline Família & Espécie & 1 & 2 & 3 & 4 & 5 & 6 & 7 & 8 & 9 & 10 \\
\hline \multirow[t]{7}{*}{ ALISMATACEAE } & Echinodorus grandiflorus Mitch. * & & & & $\mathrm{x}$ & $\mathrm{x}$ & & & & & \\
\hline & Echinodorus lanceolatus Rataj & & & & $\mathrm{x}$ & & & & & & \\
\hline & Echinodorus sp. & & & $\mathrm{x}$ & & & & & & & \\
\hline & Echinodorus tenellus (Mart.) Buch. * & & & $\mathrm{x}$ & & $\mathrm{x}$ & & & $\mathrm{x}$ & & \\
\hline & Sagittaria cf. rhombifolia Cham. * & & & & $\mathrm{x}$ & $\mathrm{x}$ & & & $\mathrm{x}$ & & \\
\hline & Sagittaria guayanensis Kunth & & & $\mathrm{x}$ & $\mathrm{x}$ & & & & & & \\
\hline & Sagittaria sp. & & & & & & & & & & $\mathrm{x}$ \\
\hline \multirow[t]{4}{*}{ APIACEAE } & Centella asiatica $($ L.) Urb. * & $\mathrm{x}$ & & & & & & & & & \\
\hline & Eryngium pandanifolium Cham. \& Schltdl. * & & $\mathrm{x}$ & $\mathrm{x}$ & $\mathrm{x}$ & & & & & & \\
\hline & Hydrocotyle leucocephala Cham. \& Schltdl. & $\mathrm{x}$ & & & & & & & & & \\
\hline & Hydrocotyle ranunculoides $\mathrm{L}$. f. & & & & & $\mathrm{x}$ & & & & & \\
\hline ARACEAE & Philodendron uliginosum Мауо & & & & & $\mathrm{x}$ & & & & $\mathrm{x}$ & \\
\hline \multirow{16}{*}{ ASTERACEAE } & Achyrocline satureioides (Lam.) DC. * & & $\mathrm{x}$ & & & & & & & & \\
\hline & Ageratum fastigiata Benth. ex Baker & & & & & & & $\mathrm{x}$ & & & \\
\hline & Baccharis aff. martiana Barroso & & & & & & $\mathrm{x}$ & & & & \\
\hline & Baccharis aphylla DC. & & $\mathrm{x}$ & & & & & & & & \\
\hline & Baccharis tridentata Vahl & & & & & & $\mathrm{x}$ & & & & \\
\hline & Cyrtocymura scorpioides (Lam.) H. Rob. * & $\mathrm{x}$ & & & & & & & & & \\
\hline & Eclipta prostrata (L.) L. * & & & & & & & & $\mathrm{x}$ & & $\mathrm{x}$ \\
\hline & Emilia sonchifolia (L.) DC. * & & & & & & & & $\mathrm{x}$ & & \\
\hline & Erechtites hieraciifolia (L.) Raf. ex DC. * & & & $\mathrm{x}$ & & & & & & & \\
\hline & Eupatorium amygdalinum Lam. & & $\mathrm{x}$ & & & & & & & & \\
\hline & Gochnatia hatschbachii Cabrera & & & & & & & & & $\mathrm{x}$ & \\
\hline & Inulopsis scoposa O. Hoffm. & & $\mathrm{x}$ & & & & & & & & \\
\hline & Lychnophora trichocarpha Spreng. & & & & & & & & & $\mathrm{x}$ & \\
\hline & Parthenium hysterophorus L. * & $\mathrm{x}$ & & & & & & & & & \\
\hline & Pluchea oblonfolia DC. & & $\mathrm{x}$ & & & & & & & & \\
\hline & Stevia lundiana DC. & & & $\mathrm{x}$ & & & & & & & \\
\hline BEGONIACEAE & Begonia cucullata Willd. * & & & & & $\mathrm{x}$ & & & & & \\
\hline \multirow[t]{3}{*}{ BORAGINACEAE } & Cordia curassavica (Jacq.) Roem. \& Schult. * & & & & & $\mathrm{x}$ & & & & & \\
\hline & Heliotropium indicum L. * & & & & & & & & $\mathrm{x}$ & & \\
\hline & Heliotropium paradoxum Gürke & & & $\mathrm{x}$ & & & & & & & \\
\hline \multirow[t]{2}{*}{ BURMANNIACEAE } & Burmannia bicolor Mart. & & & & & & & & & $\mathrm{x}$ & \\
\hline & Burmannia capitata (Walter ex J. F. Gmel.) Mart. & & & & & & & $\mathrm{x}$ & & & \\
\hline \multirow[t]{2}{*}{ CABOMBACEAE } & Cabomba caroliniana A.Gray * & & & & & & & & & & $\mathrm{x}$ \\
\hline & Cabomba furcata Schult. \& Schult. f. & & & $\mathrm{x}$ & & & & & & & $\mathrm{x}$ \\
\hline CAMPANULACEAE & Siphocampylus sp. & & & & & $\mathrm{x}$ & & & & & \\
\hline \multirow[t]{2}{*}{ COMMELINACEAE } & Commelina diffusa Burm. f. * & & & & $\mathrm{x}$ & & & & & & $\mathrm{x}$ \\
\hline & Commelina sp. & $\mathrm{x}$ & & & & & & & & & \\
\hline CONVOLVULACEAE & Evolvulus glomeratus Nees \& Mart. & & & & & & & & & & $\mathrm{x}$ \\
\hline \multirow[t]{3}{*}{ CYPERACEAE } & Ascolepis brasiliensis (Kunth) Benth. ex Clarke & & & & & & $\mathrm{x}$ & & & & \\
\hline & Cyperus eragrostis Lam. * & & $\mathrm{x}$ & & $\mathrm{x}$ & & & & & & \\
\hline & Cyperus haspan $\mathrm{L}$. & $\mathrm{x}$ & $\mathrm{x}$ & $\mathrm{x}$ & $\mathrm{x}$ & $\mathrm{x}$ & & $\mathrm{x}$ & & & $\mathrm{x}$ \\
\hline
\end{tabular}


continua

\begin{tabular}{|c|c|c|c|c|c|c|c|c|c|c|c|}
\hline Família & Espécie & 1 & 2 & 3 & 4 & 5 & 6 & 7 & 8 & 9 & 10 \\
\hline & Cyperus lanceolatus Poir. * & $\mathrm{x}$ & & & $\mathrm{X}$ & $\mathrm{x}$ & & & & & \\
\hline & Cyperus luzulae (L.) Rottb. * & & & $\mathrm{X}$ & & & & $\mathrm{X}$ & $\mathrm{X}$ & & $\mathrm{X}$ \\
\hline & Cyperus megapotamicus (Spreng.) Kunth & & $\mathrm{x}$ & & & & & & & & \\
\hline & Cyperus meyenianus Kunth * & $\mathrm{X}$ & & $\mathrm{X}$ & & & $\mathrm{X}$ & $\mathrm{X}$ & & & \\
\hline & Cyperus mundulus Kunth & & & & & & & & & & $\mathrm{x}$ \\
\hline & Cyperus polystachyus Rottb. * & & $\mathrm{x}$ & & & & & & & & \\
\hline & Cyperus prolixus Kunth & & $\mathrm{x}$ & $\mathrm{X}$ & $\mathrm{X}$ & & & $\mathrm{X}$ & & & \\
\hline & Cyperus sesquiflorus (Torr.) Mattf. \& Kük. * & $\mathrm{X}$ & & & & & & & & & \\
\hline & Cyperus virens Michx. & & & & $\mathrm{X}$ & & & & $\mathrm{X}$ & & $\mathrm{x}$ \\
\hline & Eleocharis acutangula (Roxb.) Schult. * & & $\mathrm{X}$ & & $\mathrm{x}$ & $\mathrm{X}$ & & & & & $\mathrm{x}$ \\
\hline & Eleocharis capillacea Kunth & & $\mathrm{x}$ & & & & & & & & \\
\hline & Eleocharis debilis Kunth & $\mathrm{X}$ & $\mathrm{x}$ & & & & & & & & \\
\hline & Eleocharis filiculmis Kunth * & $\mathrm{x}$ & & & $\mathrm{X}$ & & & $\mathrm{x}$ & & & \\
\hline & Eleocharis glauco-virens Boeck. & $\mathrm{x}$ & & & & & & $\mathrm{x}$ & & & \\
\hline & Eleocharis interstincta (Vahl) Roem. \& Schult. * & & & $\mathrm{X}$ & & & & & $\mathrm{X}$ & & $\mathrm{x}$ \\
\hline & Eleocharis maculosa (Vahl) Roem. \& Schult. & $\mathrm{X}$ & & & & & & & & & \\
\hline & Eleocharis minima Kunth & $\mathrm{x}$ & & $\mathrm{X}$ & & & & & & $\mathrm{X}$ & \\
\hline & Eleocharis montana (Kunth) Roem. \& Schult. & & & & & & & $\mathrm{X}$ & $\mathrm{X}$ & & \\
\hline & Eleocharis nana Kunth & & & & & & & $\mathrm{x}$ & $\mathrm{x}$ & $\mathrm{X}$ & \\
\hline & Eleocharis sellowiana Kunth * & $\mathrm{X}$ & & & $\mathrm{X}$ & $\mathrm{X}$ & & $\mathrm{x}$ & & & $\mathrm{x}$ \\
\hline & Eleocharis sp. & & & & & & & & & & $\mathrm{x}$ \\
\hline & Fimbristylis autumnalis (L.) Roem. \& Schult. * & $\mathrm{X}$ & $\mathrm{X}$ & & & & & $\mathrm{X}$ & & & \\
\hline & Fuirena umbellata Rottb. * & & & & $\mathrm{X}$ & & & $\mathrm{x}$ & $\mathrm{X}$ & & \\
\hline & Lagenocarpus sp. & & $\mathrm{x}$ & & & & & & & & \\
\hline & Lipocarpha sellowiana Kunth & & $\mathrm{x}$ & & $\mathrm{X}$ & & & & & & \\
\hline & Pleurostachys sp. & & & & & & $\mathrm{X}$ & & & & \\
\hline & Rhynchospora cf. legrandii Kük. & & & $\mathrm{X}$ & & & & & & & \\
\hline & Rhynchospora corymbosa (L.) Britton * & $\mathrm{X}$ & & & $\mathrm{X}$ & $\mathrm{x}$ & & $\mathrm{X}$ & $\mathrm{X}$ & & $\mathrm{X}$ \\
\hline & Rhynchospora emaciata (Nees) Boeck. & & $\mathrm{x}$ & & & & & & & & \\
\hline & Rhynchospora globosa Roem. \& Schult. & & $\mathrm{x}$ & & & & & & & & \\
\hline & Rhynchospora marisculus Lindl. \& Nees & $\mathrm{x}$ & $\mathrm{x}$ & $\mathrm{X}$ & & & & & & & \\
\hline & Rhynchospora nervosa (Vahl) Boeck. * & & $\mathrm{x}$ & & & & & & & & \\
\hline & Rhynchospora rugosa (Vahl) Gale & & & & & & & $\mathrm{X}$ & & & \\
\hline & Rhynchospora sp. & & & $\mathrm{x}$ & $\mathrm{X}$ & & & & & & \\
\hline & Scleria hirtella Sw. & $\mathrm{X}$ & $\mathrm{X}$ & & & & & & & & \\
\hline & Scleria mitis Berg. & & & & & & & $\mathrm{X}$ & & & \\
\hline & Scleria sp. & $\mathrm{X}$ & & & & & & & & & \\
\hline DROSERACEAE & Drosera communis A. St.-Hil. & & $\mathrm{x}$ & & & & & & & $\mathrm{X}$ & \\
\hline & Drosera montana A. St.-Hil. & & $\mathrm{x}$ & & & & & & & $\mathrm{x}$ & \\
\hline ERIOCAULACEAE & Eriocaulon aquatile Koern. & & & & & & $\mathrm{X}$ & & & $\mathrm{x}$ & \\
\hline & Eriocaulon elichrysoides Kunth & & & & & $\mathrm{x}$ & & & & & \\
\hline & Leiothrix flavescens (Bong.) Ruhland & & $\mathrm{x}$ & & & & & & & & \\
\hline & Leiothrix fluitans (Mart.) Ruhland & & & & & & $\mathrm{X}$ & & & $\mathrm{x}$ & \\
\hline & Leiothrix sp1. & & & & & & & & & $\mathrm{x}$ & \\
\hline & Leiothrix sp2. & & $\mathrm{x}$ & & & & & & & & \\
\hline & Paepalanthus flaccidus (Bong.) Kunth & & $\mathrm{x}$ & & & & & & & & \\
\hline & Paepalanthus sp. & & & & & & & $\mathrm{X}$ & & & \\
\hline & Syngonanthus caulescens (Poir.) Ruhland & $\mathrm{X}$ & $\mathrm{X}$ & & $\mathrm{X}$ & & $\mathrm{X}$ & & & & \\
\hline & Syngonanthus gracilis Ruhland & & & & & & & & & $\mathrm{X}$ & \\
\hline & Syngonanthus hygrotrichus Ruhland & $\mathrm{X}$ & & & & & & & & & \\
\hline EUPHORBIACEAE & Chamaesyce hyssopifolia (L.) Small & & $\mathrm{X}$ & & & & & & & & \\
\hline
\end{tabular}




\begin{tabular}{|c|c|c|c|c|c|c|c|c|c|c|c|}
\hline Família & Espécie & 1 & 2 & 3 & 4 & 5 & 6 & 7 & 8 & 9 & 10 \\
\hline & Croton glandulosus L. * & & & $\mathrm{x}$ & & & & & & & \\
\hline & Sapium glandulatum (Vell.) Pax & & & & & & & & $\mathrm{X}$ & & \\
\hline \multirow[t]{9}{*}{ FABACEAE } & Aeschynomene paniculata Willd. ex Vogel * & & & $\mathrm{X}$ & & & & & & & \\
\hline & Calliandra fasciculata Benth. & & & & & & $\mathrm{X}$ & $\mathrm{x}$ & & $\mathrm{X}$ & \\
\hline & Calliandra parviflora Benth. & & & & & & & & $\mathrm{X}$ & & \\
\hline & Chamaecrista nictitans subsp. pattelaria (Collad.) & & & & & & & & & & \\
\hline & H. S. Irwin \& Barneby & & & & & & & & $\mathrm{X}$ & & \\
\hline & Collaea cf. cipoensis R. Fortunato & & & & & & $\mathrm{x}$ & & & & \\
\hline & Crotalaria foliolosa Benth. & & & & & & $\mathrm{x}$ & & & & \\
\hline & Desmodium incanum DC. * & & & & & & & & $\mathrm{X}$ & & \\
\hline & Stylosanthes guianensis (Aubl.) Sw. * & & & & & & & & $\mathrm{x}$ & & \\
\hline \multirow[t]{2}{*}{ GENTIANACEAE } & Curtia tenuifolia (Aubl.) Knobl. & & & & & & & & & $\mathrm{X}$ & \\
\hline & Schultesia angustifolia Griseb. & & $\mathrm{X}$ & & & & & & & & \\
\hline GESNERIACEAE & Sinningia sp. & $\mathrm{X}$ & & & & & & & & & \\
\hline GLEICHENIAEAE & Sticherus penniger (Mart.) T. Moore & $\mathrm{x}$ & & & & & & & & & \\
\hline HALORAGACEAE & Myriophyllum aquaticum (Vell.) Verdc. ${ }^{*}$ & & & & $\mathrm{X}$ & & & & & & \\
\hline HYDROCHARITACEAE & Apalanthe granatensis (Humb. \& Bonpl.) Planch. & & & & & & $\mathrm{X}$ & & $\mathrm{x}$ & & \\
\hline HYDROLEACEAE & Hydrolea spinosa L. * & & & & $\mathrm{X}$ & $\mathrm{X}$ & & & & & \\
\hline HYPERICACEAE & Hypericum brasiliense Choisy & $\mathrm{X}$ & & & & $\mathrm{x}$ & & & & & \\
\hline \multirow[t]{2}{*}{ IRIDACEAE } & Sisyrinchium avenaceum Klatt & $\mathrm{x}$ & & & & & & & & & \\
\hline & Trimezia juncifolia (Klatt) Benth. & & $\mathrm{x}$ & & & & & & & & \\
\hline \multirow[t]{2}{*}{ JUNCACEAE } & Juncus densiflorus Kunth & & $\mathrm{x}$ & & & & & & & & \\
\hline & Juncus sellowianus Kunth * & & $\mathrm{x}$ & & & & & & & & \\
\hline \multirow[t]{2}{*}{ LAMIACEAE } & Hyptis brevipes Poit. * & & & $\mathrm{x}$ & & & & & $\mathrm{X}$ & & $\mathrm{x}$ \\
\hline & Hyptis sp. & $\mathrm{X}$ & & & & & & & & & \\
\hline \multirow[t]{8}{*}{ LENTIBULARIACEAE } & Genlisea pygmaca A. St.-Hil. & & & & & & & & & & \\
\hline & Utricularia amethystina Salzm. ex A. St.-Hil. \& Girard & & $\mathrm{x}$ & & & & & & & & \\
\hline & Utricularia breviscapa Wright ex Griseb. & & & $\mathrm{X}$ & & & & & & & $\mathrm{x}$ \\
\hline & Utricularia gibba L. * & $\mathrm{X}$ & & $\mathrm{x}$ & $\mathrm{X}$ & $\mathrm{x}$ & & & $\mathrm{X}$ & & $\mathrm{x}$ \\
\hline & Utricularia neottioides A. St.-Hil. \& Girard & & & & & & $\mathrm{X}$ & & & $\mathrm{x}$ & \\
\hline & Utricularia nervosa G. Weber \& Benj. & & $\mathrm{x}$ & & & & & $\mathrm{x}$ & & $\mathrm{x}$ & \\
\hline & Utricularia praelonga A. St.-Hil. \& Girard & & $\mathrm{x}$ & & & & & & & & \\
\hline & Utricularia sp. & & & & & $\mathrm{X}$ & & & & & \\
\hline \multirow[t]{2}{*}{ LYCOPODIACEAE } & Lycopodiella alopecuriodes (L.) Cranfill & & $\mathrm{x}$ & & & & & & & & \\
\hline & Lycopodiella cernua (L.) Pic. Serm. & & & & & & $\mathrm{X}$ & & & & \\
\hline \multirow[t]{6}{*}{ LYTHRACEAE } & Cuphea cf. sessilifolia Mart. & & & & & & & $\mathrm{x}$ & & & \\
\hline & Cuphea fuscinervis Koehne & $\mathrm{X}$ & & $\mathrm{X}$ & & & & & & & \\
\hline & Cuphea ingrata Cham. \& Schltdl. & $\mathrm{x}$ & & & & & & & & & \\
\hline & Cuphea repens Koehne & & & $\mathrm{x}$ & & & & & & & \\
\hline & Cuphea sp.1 & & $\mathrm{x}$ & & & & & & & & \\
\hline & Cuphea sp.2 & & & & $\mathrm{X}$ & & & & & & \\
\hline MALPIGHIACEAE & Camarea affinis A.St.-Hil. & & $\mathrm{X}$ & & & & & & & & \\
\hline \multirow[t]{2}{*}{ MALVACEAE } & Sida ciliaris L. & & & & & & & & & & $\mathrm{x}$ \\
\hline & Melochia villosa (Mill.) Fawc. \& Rendle. & & & $\mathrm{x}$ & & & & & & & $\mathrm{x}$ \\
\hline \multirow[t]{2}{*}{ MAYACACEAE } & Mayaca fluviatilis Aubl. & $\mathrm{X}$ & $\mathrm{x}$ & $\mathrm{x}$ & & $\mathrm{X}$ & $\mathrm{X}$ & $\mathrm{X}$ & & & \\
\hline & Mayaca sellowiana Kunth & & $\mathrm{x}$ & $\mathrm{x}$ & & $\mathrm{x}$ & $\mathrm{x}$ & & & & \\
\hline \multirow[t]{5}{*}{ MELASTOMATACEAE } & Acisanthera alsinaefolia (DC.) Triana & $\mathrm{X}$ & $\mathrm{x}$ & & $\mathrm{X}$ & $\mathrm{x}$ & & & & & \\
\hline & Lavoisiera bergii Cong. & & $\mathrm{x}$ & & & & $\mathrm{X}$ & & & & \\
\hline & Macairea radula (Bonpl.) DC. & & & & & & & $\mathrm{X}$ & & $\mathrm{X}$ & \\
\hline & Microlicia confertiflora Naudin & & $\mathrm{X}$ & & & & & & & & \\
\hline & Microlicia isophylla DC. & & & & & $\mathrm{X}$ & & $\mathrm{x}$ & & $\mathrm{x}$ & \\
\hline
\end{tabular}


continua

\begin{tabular}{|c|c|c|c|c|c|c|c|c|c|c|c|}
\hline Família & Espécie & 1 & 2 & 3 & 4 & 5 & 6 & 7 & 8 & 9 & 10 \\
\hline & Pterolepis glomerata Miq. & & & & & $\mathrm{x}$ & & & & & \\
\hline & Rhynchanthera cordata DC. & $\mathrm{X}$ & $\mathrm{X}$ & & & $\mathrm{x}$ & & & & & \\
\hline & Rhynchanthera grandiflora (Aubl.) DC. & $\mathrm{x}$ & & $\mathrm{x}$ & $\mathrm{X}$ & $\mathrm{x}$ & & & & & \\
\hline & Siphanthera cordata Pohl & & & $\mathrm{x}$ & & & & & & & \\
\hline & Tibouchina gracilis (Bonpl.) Cogn. * & $\mathrm{X}$ & & $\mathrm{x}$ & & & & & & & \\
\hline & Trembleya phlogiformis DC. & & & & & & $\mathrm{x}$ & & & & \\
\hline MENYANTHACEAE & Nymphoides indica (L.) Kuntze * & & & $\mathrm{X}$ & $\mathrm{X}$ & $x$ & & & $x$ & & $\mathrm{X}$ \\
\hline NAJADACEAE & Najas microcarpa K. Schum. & & & $\mathrm{x}$ & & & & & $\mathrm{x}$ & & $\mathrm{x}$ \\
\hline NYMPHAEACEAE & Nymphaea ampla (Salisb.) DC. * & & & & $\mathrm{x}$ & & & & $\mathrm{x}$ & & $\mathrm{x}$ \\
\hline \multirow[t]{2}{*}{ OCHNACEAE } & Sauvagesia erecta L. & $\mathrm{X}$ & & $\mathrm{X}$ & & & & $\mathrm{X}$ & & & \\
\hline & Sauvagesia racemosa A. St.-Hil. & & $\mathrm{X}$ & & & $\mathrm{x}$ & & & & & \\
\hline \multirow[t]{8}{*}{ ONAGRACEAE } & Ludwigia brachyphylla (Micheli) H. Hara & & & & & & & & & & $\mathrm{X}$ \\
\hline & Ludwigia laruotteana (Cambess.) H. Hara * & & & & & & & & & & $\mathrm{x}$ \\
\hline & Ludwigia leptocarpa (Nutt.) H. Hara * & $\mathrm{X}$ & & & & $\mathrm{X}$ & & & & & $\mathrm{x}$ \\
\hline & Ludwigia myrtifolia (Cambess.) H. Hara & & & $\mathrm{x}$ & $\mathrm{X}$ & $\mathrm{x}$ & $\mathrm{X}$ & & & & \\
\hline & Ludwigia nervosa (Poir.) H. Hara & $\mathrm{X}$ & $\mathrm{X}$ & & & $\mathrm{x}$ & & $\mathrm{X}$ & $\mathrm{X}$ & & \\
\hline & Ludwigia octovalvis (Jacq.) P. H. Raven * & & & & $\mathrm{X}$ & & & & & & $\mathrm{x}$ \\
\hline & Ludwigia peploides (Kunth) P. H. Raven & & & & & & & & $\mathrm{X}$ & & \\
\hline & Ludwigia tomentosa (Cambess.) H. Hara * & $\mathrm{X}$ & & & & & & & $\mathrm{x}$ & & \\
\hline \multirow[t]{2}{*}{ ORCHIDACEAE } & Habenaria parviflora Lindl. & & $\mathrm{X}$ & & & & & & & & \\
\hline & Oncidium barbaceniae Lindl. & & $\mathrm{x}$ & & & & & & & & \\
\hline OROBANCHACEAE & Esterhazya macrodonta Cham. \& Schltdl. & & $\mathrm{x}$ & & & & & & & & \\
\hline OSMUNDACEAE & Osmunda regalis $\mathrm{L}$. & & & & & $\mathrm{x}$ & & & & & \\
\hline PIPERACEAE & Piper sp. & & & & & & & & $\mathrm{x}$ & & \\
\hline \multirow[t]{2}{*}{ PLANTAGINACEAE } & Bacopa salzmannii Wettst. ex Edwall & $\mathrm{X}$ & & & & $\mathrm{X}$ & & & & & $\mathrm{x}$ \\
\hline & Mecardonia serpylloides (Cham. \& Schltdl.) Pennell & $\mathrm{x}$ & & & & & & & & & \\
\hline \multirow[t]{23}{*}{ POACEAE } & Andropogon bicornis L. * & $\mathrm{x}$ & & & & & & & & & \\
\hline & Andropogon virgatus Desv. & & & & & & $\mathrm{X}$ & $\mathrm{X}$ & & $\mathrm{X}$ & \\
\hline & Arundinella hispida (Willd.) Kuntze & $\mathrm{X}$ & & & & & & & & & \\
\hline & Axonopus aureus P. Beauv. & & $\mathrm{x}$ & & & & & & & & \\
\hline & Briza calotheca (Trin.) Hack. & & $\mathrm{x}$ & & & & & & & & \\
\hline & Eriochrysis cayennensis P. Beauv. & $\mathrm{x}$ & $\mathrm{x}$ & & & & & & & & \\
\hline & Ichnanthus procurrens (Nees ex Trin.) Swallen & & & $\mathrm{X}$ & & & & & & & \\
\hline & Loudetia flammida (Trin.) C. E. Hubb. & & & & & & $\mathrm{x}$ & $\mathrm{X}$ & & & \\
\hline & Luziola bahiensis (Steud.) Hitchc. & $\mathrm{X}$ & & & & & & & & & \\
\hline & Otachyrium aquaticum Send. \& Soderstr. & & & & & & $\mathrm{X}$ & & & $\mathrm{X}$ & \\
\hline & Otachyrium versicolor (Döll) Henrard & & & $\mathrm{x}$ & & & & & & & \\
\hline & Panicum aquaticum Poir. & & & & & & & & & & $\mathrm{X}$ \\
\hline & Panicum cf. schwackeanum Mez & & & $\mathrm{x}$ & & & & & & & $\mathrm{x}$ \\
\hline & Panicum laxum Swartz & $\mathrm{x}$ & & $\mathrm{x}$ & & & & & & & $\mathrm{x}$ \\
\hline & Panicum parvifolium Lam. * & $\mathrm{x}$ & & & & $\mathrm{X}$ & & $\mathrm{X}$ & & & \\
\hline & Panicum pernambucense (Spreng.) Mez ex Pilg. & & & $\mathrm{x}$ & $\mathrm{X}$ & & & & & & \\
\hline & Panicum sp.1 & & & & & & & $\mathrm{x}$ & & & \\
\hline & Panicum sp.2 & & & & & & & $\mathrm{x}$ & & & \\
\hline & Panicum sp.3 & & & $\mathrm{X}$ & & & & & & & \\
\hline & Sacciolepis vilvoides (Trin.) Chase & & $\mathrm{X}$ & & $\mathrm{X}$ & & & & & & $\mathrm{X}$ \\
\hline & Steinchisma decipiens (Nees) W. V. Brown & $\mathrm{X}$ & $\mathrm{x}$ & & & & & $\mathrm{X}$ & & $\mathrm{X}$ & \\
\hline & Steinchisma hians (Elliott) Nash & & & & & & & $\mathrm{x}$ & & & \\
\hline & Thrasya cf. thrasyoides (Trin.) Chase & & $\mathrm{X}$ & & & & & & & & \\
\hline \multirow[t]{2}{*}{ PODOSTEMACEAE } & Cipoia ramosa Bove \& C. T. Philbrick & & & & & & $\mathrm{x}$ & & & & \\
\hline & Diamantina lombardii Novello C. T. Philbrick \& Irgang & & & & & & & & & $\mathrm{X}$ & \\
\hline
\end{tabular}


continua

\begin{tabular}{|c|c|c|c|c|c|c|c|c|c|c|c|}
\hline Família & Espécie & 1 & 2 & 3 & 4 & 5 & 6 & 7 & 8 & 9 & 10 \\
\hline \multirow[t]{3}{*}{ POLYGALACEAE } & Bredemeyera martiana A. W. Benn. & & & & & & $\mathrm{x}$ & & & & \\
\hline & Monnina stenophylla A. St.-Hil. & & & $\mathrm{x}$ & & & & & & & \\
\hline & Polygala paniculata L. * & & $\mathrm{X}$ & $\mathrm{x}$ & & & & & & & \\
\hline \multirow[t]{4}{*}{ POLYGONACEAE } & Polygonum acuminatum Kunth * & & & $\mathrm{x}$ & & $\mathrm{X}$ & & & $\mathrm{x}$ & & $\mathrm{x}$ \\
\hline & Polygonum ferrugineum Wedd. & & & $\mathrm{x}$ & & & & & $\mathrm{x}$ & & \\
\hline & Polygonum hydropiperoides Michx. * & & & & $\mathrm{x}$ & & & & $\mathrm{x}$ & & $\mathrm{x}$ \\
\hline & Polygonum meissnerianum Cham. \& Schltdl. & & & $\mathrm{x}$ & $\mathrm{x}$ & $\mathrm{x}$ & & & $\mathrm{x}$ & & $\mathrm{x}$ \\
\hline \multirow[t]{5}{*}{ PONTEDERIACEAE } & Eichhornia azurea (Sw.) Kunth * & & & & $\mathrm{x}$ & $\mathrm{x}$ & & & & & \\
\hline & Eichhornia crassipes (Mart.) Solms * & & & & $\mathrm{x}$ & & & & & & \\
\hline & Heteranthera reniformis Ruiz \& Pavón * & & & & & & & & & & $\mathrm{x}$ \\
\hline & Pontederia cordata L. * & & & & & & $\mathrm{x}$ & & & & \\
\hline & Pontederia parviflora Alexander & & & & $\mathrm{x}$ & $\mathrm{x}$ & $\mathrm{x}$ & & & & \\
\hline \multirow[t]{6}{*}{ RUBIACEAE } & Augusta longifolia (Spreng.) Rehder & & & & & & & $\mathrm{x}$ & & $\mathrm{x}$ & \\
\hline & Diodia alata Nees \&t Mart. * & & & $\mathrm{x}$ & & $\mathrm{x}$ & & & $\mathrm{x}$ & & \\
\hline & Hedyotis thesiifolia A. St.-Hil. & & & $\mathrm{x}$ & & & & & $\mathrm{x}$ & & \\
\hline & Mitracarpus brasiliensis M. L. Porto \& Waechter & $\mathrm{X}$ & & & & & & & & & \\
\hline & Perama hirsuta Aubl. & & & & & & & & & $\mathrm{x}$ & \\
\hline & Spermacoce verticillata $\mathrm{L}$. & & & & & & & $\mathrm{x}$ & & & \\
\hline SOLANACEAE & Schwenckia curviflora Benth. & & & & & $\mathrm{x}$ & & & & & \\
\hline \multirow[t]{2}{*}{ THELYPTERIDACEAE } & Thelypteris rivularioides (Fée) Abbiatti & $\mathrm{x}$ & & & & & & & & & \\
\hline & Thelypteris salzmannii (Fée) C.V. Morton & $\mathrm{x}$ & & & & & & & & & \\
\hline TYPHACEAE & Typha domingensis Pers. * & & & & & $\mathrm{x}$ & & & $\mathrm{x}$ & & $\mathrm{x}$ \\
\hline \multirow[t]{7}{*}{ XYRIDACEAE } & Xyris cf. diaphanobracteata Kral \& Wand. & & & & $\mathrm{x}$ & & & & & & \\
\hline & Xyris jupicai Rich. & & & & & $\mathrm{x}$ & & & & & \\
\hline & Xyris laxifolia Mart. & $\mathrm{x}$ & & $\mathrm{x}$ & $\mathrm{x}$ & $\mathrm{x}$ & $\mathrm{x}$ & $\mathrm{x}$ & & & \\
\hline & Xyris savannensis Miq. & $\mathrm{x}$ & $\mathrm{X}$ & $\mathrm{x}$ & & & & $\mathrm{x}$ & & & \\
\hline & Xyris schizachne Mart. & & $\mathrm{x}$ & & $\mathrm{x}$ & & & & & & \\
\hline & Xyris aff. tenella Kunth & & & & & & & & & $\mathrm{x}$ & \\
\hline & Xyris sp. & & $\mathrm{X}$ & & $\mathrm{x}$ & & $\mathrm{x}$ & $\mathrm{x}$ & & & \\
\hline
\end{tabular}

* = Espécies endêmicas do Estado de Minas Gerais / Endemic species of Minas Gerais State; * = Espécies invasoras / Invasive species.

barbaceniae para a bacia do Rio Doce e Cipoia ramosa, Pontederia cordata, Pontederia parviflora, Eichhornia azurea e Eichhornia crassipes para a bacia do Rio São Francisco.

As áreas com maior riqueza em número de espécies foram: Lagoa Nascentes do Taboão (60), Lagoa Tanque da Fazenda (53), Lagoa Comprida (49) e Lagoa Arame (42).

Os valores do índice de similaridade florística de Jaccard variaram entre 0 e 0,2570 (tabela 3 ), o que demonstrou, no geral, uma baixa similaridade florística entre as áreas. As áreas com maiores valores de similaridade entre elas foram: Lagoa Arame e Lagoa Terra de Arroz (0,2570), e os Açudes Americana e Estivinha (0,2370). Três pares de comparações não apresentaram similaridade florística: (a) Rio Corrento e Estivinha, (b) Rio Preto e Estivinha e (c) Rio Preto e Lagoa Terra de Arroz.

Os ambientes lóticos estiveram representados por três áreas de amostragem, apresentando uma riqueza de
72 espécies, o que correspondeu a aproximadamente $32,58 \%$ do total de espécies amostradas. As famílias Podostemaceae e Burmanniaceae tiveram sua ocorrência registrada somente nos rios e 40 espécies foram exclusivas desses ambientes. Podem ser citadas as seguintes espécies Eriocaulon aquatile, Leiothrix fluitans, Utricularia neottioides, Diamantina lombardii, Burmannia bicolor, Burmannia capitata, Genlisea pygmaea, Otachyrium aquaticum, Loudetia flammida, Steinchisma hians e Augusta longifolia, dentre outras (tabela 2). Cabe ressaltar que a Asteraceae Gochnatia hatschbachii está presente na lista de espécies ameaçadas de extinção da Flora de Minas Gerais, citada na categoria de vulnerável (Mendonça \& Lins 2000) e no Rio Corrento foi amostrada a espécie nova Cipoia ramosa, cujo material foi descrito a partir desse estudo (Bove \& Philbrick 2006).

A análise aglomerativa (figura 2) distinguiu o grupo composto pelos Rios Corrento e Rio Preto das demais 
Tabela 3. Índice de Jaccard entre dez áreas em ambientes úmidos na Cadeia do Espinhaço (Minas Gerais, Brasil).

Table 3. Jaccard indices among ten areas of wetlands in Espinhaço Range (Minas Gerais State, Brazil).

\begin{tabular}{|c|c|c|c|c|c|c|c|c|c|c|}
\hline & TANQ & NASC & COMP & TERR & ARAM & CORR & TAQU & AMER & PRET & ESTI \\
\hline TANQ & $*$ & 0,1270 & 0,1370 & 0,1120 & 0,1700 & 0,0540 & 0,1510 & 0,0450 & 0,0320 & 0,0800 \\
\hline NASC & & $*$ & 0,0830 & 0,1120 & 0,0760 & 0,0490 & 0,0930 & 0,0100 & 0,0380 & 0,0300 \\
\hline COMP & & & $*$ & 0,1630 & 0,1410 & 0,0580 & 0,0860 & 0,1600 & 0,0110 & 0,1730 \\
\hline TERR & & & & $*$ & 0,2570 & 0,0790 & 0,0950 & 0,1300 & 0,0000 & 0,1970 \\
\hline ARAM & & & & & $*$ & 0,0890 & 0,0910 & 0,1390 & 0,0240 & 0,1530 \\
\hline CORR & & & & & & $*$ & 0,0980 & 0,0130 & 0,1700 & 0,0000 \\
\hline TAQU & & & & & & & $*$ & 0,0890 & 0,1520 & 0,0480 \\
\hline AMER & & & & & & & & $*$ & 0,0270 & 0,2370 \\
\hline PRET & & & & & & & & & $*$ & 0,0000 \\
\hline ESTI & & & & & & & & & & $*$ \\
\hline
\end{tabular}

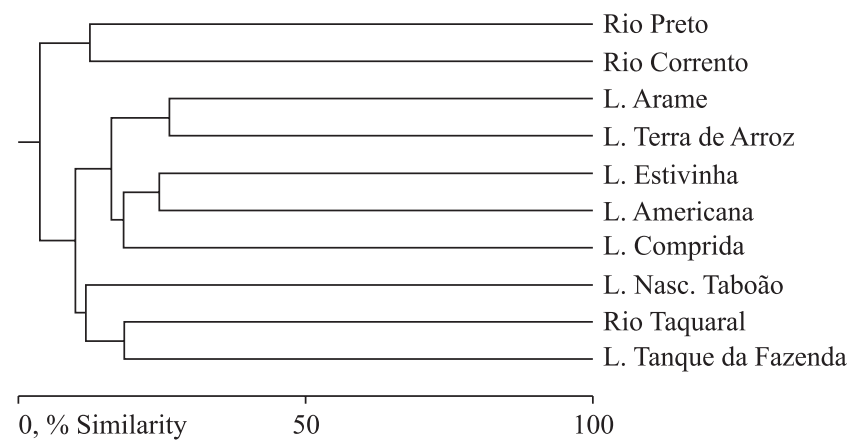

Figura 2. Análise aglomerativa da similaridade florística de Jaccard de plantas vasculares associadas a ambientes úmidos, entre as áreas de amostragem na Cadeia do Espinhaço (Minas Gerais, Brasil).

Figure 2. Agglomerative analysis of the floristic similarity of Jaccard of vascular plants associated with wetlands, among the sampling areas in the Espinhaço Range (Minas Gerais State, Brazil).

áreas de amostragem. $\mathrm{O}$ valor de similaridade entre esses rios foi de 0,1700. O Rio Taquaral, pertencente à bacia do rio Jequitinhonha, apareceu junto ao grupo das áreas Lagoa Nascentes do Taboão e Lagoa Tanque da Fazenda, ambas localizadas na bacia do Rio Doce (tabela 1).

Para os ambientes lênticos amostrados, cinco lagoas marginais e dois açudes, observou-se uma riqueza florística de 184 espécies, sendo que 152 foram amostradas somente nesses ambientes. Podem ser citadas como exclusivas as famílias Alismataceae, Najadaceae, Cabombaceae e Polygonaceae, dentre outras. Foram registradas apenas nas lagoas e açudes as espécies: Nymphaea ampla, Najas microcarpa, Utricularia breviscapa, Utricularia praelonga, Nymphoides indica, Cabomba furcata, Cabomba caroliniana, Sagittaria guayanensis, Echinodorus grandiflorus, Polygonum acuminatum, Polygonum hydropiperoides, entre outras. Destaca-se também a presença, na Lagoa Nascentes do Taboão, de Inulopsis scaposa considerada em perigo de extinção (Mendonça \& Lins 2000).

As áreas de lagoas e açudes mostraram-se mais similares, de maneira geral, em relação à maior proximidade geográfica e conforme suas respectivas bacias hidrográficas (tabelas 1 e 3, figura 2). Os ambientes lênticos foram agrupados em um conjunto composto pelas áreas da Bacia do Rio Doce e outro pelas áreas correspondentes às Bacias dos Rios São Francisco e Jequitinhonha. Dentro desses grupos foram distintas as áreas Americana e Estivinha (Jequitinhonha) e Terra de Arroz e Arame (São Francisco). Somente a Lagoa Comprida não apareceu junto às áreas correspondentes à sua bacia.

O resultado do teste de Mantel para o conjunto das áreas não foi significativo $(P=0,17)$, sendo confirmado pelo baixo valor de similaridade entre elas. No entanto, houve correlação negativa $(\mathrm{R}=-0,21)$, resultado que pode indicar que, quanto maior a distância geográfica, menor a similaridade florística entre as áreas. Esta correlação pode ser observada entre os açudes Americana e Estivinha, cuja distância entre eles foi de quinze quilômetros e o valor de similaridade maior em comparação às outras áreas mais distantes.

Das 224 espécies amostradas, 61, ou seja, aproximadamente $27 \%$, são citadas como potencialmente invasoras (Leitão Filho et al. 1972; 1975, Bacchi et al. (1984), Brandão et al. 1989, Lorenzi 2000) (tabela 2). 
As áreas com os maiores números de ocorrência de espécies invasoras foram Lagoa Terra de Arroz (22), Açude Americana (21), Açude Estivinha (19) e Lagoa Arame (19). Entre os rios a ocorrência de espécies invasoras foi menor em relação aos ambientes lacustres. No Rio Taquaral foram registradas oito espécies e no Rio Corrento apenas três. Nenhuma espécie amostrada foi indicada como invasora no Rio Preto.

\section{Discussão}

Em estudos que abordam levantamentos em ecossistemas aquáticos realizados no Brasil foram registrados números inferiores de espécies em relação ao observado para as áreas úmidas amostradas na Cadeia do Espinhaço (tabela 4). Contudo, os estudos realizados por Matias et al. (2003) e Henriques et al. (1988), que abrangeram somente o ambiente lacustre, se comparados àqueles das lagoas da Cadeia do Espinhaço apresentaram um número de espécies semelhante à média de riqueza de espécies nesses ambientes. Já a inclusão de ambientes como de florestas de galeria elevaram a riqueza nos estudos de Pedralli et al. (1993a), Pedralli et al. (1993b) e Pedralli \& Meyer (1996), bem como as áreas ecotonais no estudo de Pedralli \& Gonçalves (1997).

As diferenças em relação à riqueza de espécies em áreas úmidas podem ser atribuídas à diversidade de ambientes amostrados, ao tamanho das áreas amostradas e aos critérios de inclusão considerados nos métodos empregados para os levantamentos. Bini et al. (2001) considera o tamanho da área amostrada a variável independente que mais influencia na riqueza de espécies de plantas aquáticas.

A disponibilidade de habitats colonizáveis por macrófitas aquáticas também pode estar relacionada à riqueza florística (Espíndola et al. 2003), assim como a ocorrência de espécies invasoras. Devido a vulnerabilidade dos ecossistemas aquáticos à ação antrópica (Scremin-Dias 2000), muitos corredores ripários têm sido invadidos por espécies exóticas (Pollock et al. 1998). Estas evidências são apontadas no estudo de Pedralli \& Gonçalves (1997) que discutiram o efeito das perturbações ocorridas nas lagoas que amostraram, em relação ao incremento do número de espécies invasoras e concluíram que a riqueza aumenta em áreas perturbadas. Estudo de Brandão et al. (1989) indicaram que 113 espécies palustres e aquáticas do Estado de Minas Gerais são invasoras.

Nos ambientes amostrados na Cadeia do Espinhaço, verificou-se uma importante soma de espécies potencialmente invasoras. Nas Lagoas Terra de Arroz e Arame e nos Açudes Americana e Estivinha, nos quais foram registradas maiores ocorrências de plantas invasoras, foram também os ambientes com maiores incidências de fatores antrópicos. Em oposição, o Rio Preto, onde não foi amostrada nenhuma espécie invasora, correspondeu ao ecossistema mais conservado dentre as áreas de estudo. Contudo, não se pode concluir que a riqueza de espécies nos ambientes amostrados na Cadeia de Espinhaço foi incrementada em função da ocorrência de espécies invasoras, pois entre os ambientes lênticos, aqueles que apresentaram menor riqueza, também foram as que apresentam maiores interferências antrópicas. Conforme discutiram Pollock et al. (1998), os distúrbios ou a heterogeneidade espacial são fatores que regulam a riqueza de espécies em comunidades vegetais.

Embora os ambientes lóticos abriguem, de maneira geral, um número menor de macrófitas aquáticas (Thomaz \& Bini 2003), muitas espécies são endêmicas a eles. Os rios constituem habitats complexos influenciados por uma série de variáveis físicas, tais como: a vazão, o substrato, a largura, a profundidade, o tipo de margem,

Tabela 4. Outros estudos desenvolvidos em ambientes úmidos, localização e riqueza florística.

Table 4. Other studies developed in Brazilian wetlands, locations and species richness.

\begin{tabular}{llc}
\hline Estudo & Área & № espécies \\
\hline Scremin-Dias et al. (1999) & Planalto da Bodoquena (MS) & 46 \\
Bini et al. 2001 & Planície de inundação do alto Rio Paraná (PR) & 50 \\
Matias et al. 2003 & Lagoa de Jericoacoara (CE) & 45 \\
Henriques et al. 1988 & Lagoa Cabiúnas (RJ) & 23 \\
Pedralli \& Gonçalves (1997) & Lagoa Santa (MG) & 78 \\
Pedralli et al. (1993a) & EPDA Peti (MG) & 134 \\
Pedralli et al. (1993b) & Volta Grande (MG) & 49 \\
Pedralli \& Meyer (1996) & Nova Ponte (MG) & 99 \\
\hline
\end{tabular}


a sua posição no sistema hídrico (Haslam 1978). Além disso, as irregularidades geológicas e os obstáculos artificiais podem progressivamente modificar o seu curso e a sua composição química (Sculthorpe 1967). Toda essa multiplicidade de ambientes pode refletir na composição florística (Sculthorpe 1967, Haslam 1978). O movimento das águas constitui um dos fatores mais importantes na determinação das espécies e os cursos de água, com fluxos similares, apresentam padrões florísticos semelhantes (Haslam 1978). Provavelmente, esse aspecto influenciou a maior similaridade entre as áreas do Rio Corrento e do Rio Preto, indicadas na análise aglomerativa. Foram encontradas seis espécies em comum nesses ambientes, podendo-se destacar: Eriocaulon aquatile, Leiothrix fluitans e Utricularia neottioides. Essa última ocorre fixa nos leitos de córregos rochosos, encachoeirados ou poças de água sobre rochas (Fromm-Trinta 1996). As espécies de Eriocaulaceae, por sua vez, são citadas como ocorrentes em córregos do Brasil, apresentando forma biológica emergente ou sazonalmente submersa (Cook 1996). As características físicas desses rios são semelhantes, o substrato é rochoso em alguns trechos e ocorrem áreas de correnteza mais acentuada e zonas de remanso. As espécies citadas acima caracteristicamente foram encontradas habitando os locais de correntezas e entre rochas.

Os gêneros de Podostemaceae amostrados no estudo são endêmicos do Estado de Minas Gerais e foram descritos recentemente (Philbrick et al. 2004). Diamantina lombardii é conhecida em apenas duas localidades, Parque Estadual do Rio Preto e Rio do Peixe, e Cipoia ramosa, conhecida na APA da Serra do Cabral (Bove \& Philbrick 2006). Essa família é citada como rica em endemismos e muitas espécies são de distribuição extremamente restrita, apresentando habitat específico e poucas adaptações significativas para a dispersão (Sculthorpe 1967, Cook 1996). A grande maioria das espécies de Podostemaceae ocorre fixada às pedras, em locais de cachoeiras ou corredeiras (Hoehne 1979).

As outras ocorrências registradas como espécies endêmicas do Estado de Minas Gerais são Leiothrix fluitans e Syngonanthus hygrotrichus (P.T. Sano, dados não publicados) ambas características de riachos, Oncidium barbaceniae (R. Mota, com. pess.), Gochnatia hatschbachii (J. Nakajima, com. pess.) e Lychnophora trichocarpha (Nesom 1994), que ocorrem em áreas de campo rupestre e bordas de rios e córregos. De maneira geral, as espécies endêmicas registradas estavam presentes em margens de rios.

Cabe salientar que existem poucas informações sobre a florística dos rios (Thomaz \& Bini 2003), preocupação que se torna crescente, uma vez que, muitas espécies de macrófitas aquáticas apresentam adaptações a ambientes de corredeiras e substratos rochosos, e as alterações no habitat podem determinar a extinção da espécie naquele local. Os trechos de rios que possuem estas características, além da beleza cênica que atrai atividades antrópicas das mais variadas, constituem freqüentemente locais preferenciais para a instalação de usinas hidrelétricas.

Apesar de ser verificada a ocorrência de espécies comuns entre os Rios Corrento, Preto e Taquaral, neste último houve semelhança florística maior com as áreas de lagoas, localizadas na bacia do Rio Doce. Muitas espécies de Poaceae e Cyperaceae foram comuns entre as áreas do Rio Taquaral e as Lagoas Tanque da Fazenda e Nascentes do Taboão, destacando Steinschisma decipiens, ocorrente em margens de lagoas e córregos (Longhi-Wagner et al. 2001) e presente nas três áreas.

O trecho amostrado do Rio Taquaral caracterizouse por apresentar uma área maior de remanso e o fluxo de água não era tão intenso como observado nos outros ambientes lóticos. Ocorreram também micro habitats de solos bastante úmidos entre pedras, constituindo ambientes propícios à colonização de espécies como Andropogon virgatus, Loudetia flammida e Panicum parvifolium, citadas como ocorrentes em áreas úmidas e margens de riachos (Longhi-Wagner et al. 2001); Cyperus lanceolatus, Cyperus megapotamicus, Eleocharis nana, Eleocharis sellowiana, Fimbristylis autumnalis, presentes em locais úmidos e pantanosos (Irgang \& Gastal Junior 1996) e Mayaca fluviatilis, cuja forma biológica pode variar desde submersa, flutuante até terrestre em ambientes bastante úmidos (Pott \& Pott 2000). Na área do Rio Taquaral, essa espécie foi observada colonizando solos encharcados, entre pedras, nas margens do rio. Várias dessas espécies tiveram ocorrência também nas lagoas da Bacia do Rio Doce.

A influência da vegetação adjacente pode ter contribuído com a maior similaridade entre as áreas Tanque da Fazenda e Nascentes do Taboão. Nessas lagoas foram observadas algumas espécies comuns que ocorrem nas formações dos campos vizinhos. As seguintes espécies foram observadas tanto nos campos úmidos quanto nos campos cerrados adjacentes: Fimbristylis autumnalis, Cyperus haspan, Rhynchospora marisculus, Scleria hirtella e Eriochrysis cayennensis. A ocorrência de espécies campestres que chegam às margens de áreas úmidas pode também ter contribuído para o maior incremento no número de espécies nessas áreas, que foram responsáveis pelos maiores valores de riqueza florística dentre os ambientes estudados. 
A similaridade florística verificada entre os Açudes Americana e Estivinha, únicos ambientes lênticos amostrados na bacia do rio Jequitinhonha, relaciona-se provavelmente a proximidade entre eles. Também, essas áreas são freqüentadas pelas populações do entorno, para utilização doméstica, lazer e dessedentação de animais, o que vem gerando diversas alterações nas suas condições ambientais. Na Lagoa Comprida, localizada no Parque Nacional da Serra do Cipó, observou-se similaridade florística com as lagoas citadas acima, apesar da Lagoa Terra de Arroz ser bem próxima, geograficamente, apenas cinco quilômetros de distância. Entretanto, ao longo do estudo, foram observadas interferências que podem ter colaborado para a ocorrência de espécies invasoras, aumentando assim as similaridades entre áreas distantes. Aparecem em comum, nessas áreas: Cyperus haspan, Cyperus lanceolatus, Cyperus luzulae, Hyptis brevipes e Rhynchospora corymbosa, citadas por Pott $\&$ Pott (2000) e Lorenzi (2000) como plantas invasoras e ocasionalmente aquáticas. Além dessas espécies, observou-se também a presença de Typha domingensis nos Açudes Americana e Estivinha e Nymphoides indica, nos três ambientes. Nymphoides indica e T. domingensis também ocorrem em locais de perturbação antrópica (Pott \& Pott 2000, Lorenzi 2000). Outra característica marcante é a presença de Eleocharis interstincta que, segundo Pott \& Pott (2000), pode indicar uma fase intermediária de sucessão, às vezes, podendo tornarse dominante nas margens da lagoa até o centro. Esta espécie foi observada nas três áreas, porém ocorre uma população bastante expressiva na área Estivinha.

As Lagoas Terra de Arroz e Arame, pertencentes à bacia do Rio São Francisco, apresentaram o maior valor de similaridade $(0,26)$, apesar de não se situarem muito próximas. Somente três espécies estiveram presentes exclusivamente nestas áreas: Echinodorus grandiflorus, Hydrolea spinosa e Eichhornia azurea. Todas elas citadas como ocorrentes em solos férteis (Pott \& Pott 2000). Uma característica evidenciada nesses locais é a presença de áreas cultivadas.

Os baixos valores de similaridade florística entre as áreas amostradas podem estar associados ao grande número de espécies que apareceram em apenas uma área. Este fato, também foi determinante para o elevado valor verificado para o estimador "Jackknife". Cabe ressaltar que o cálculo de estimadores de riqueza constitui uma importante ferramenta para se avaliar a diversidade gama, em virtude da dificuldade de se amostrar todas as espécies ocorrentes em uma região, como sugeriram Bini et al. (2001). A diferença entre os valores de riqueza observados e o cálculo do estimador "Jackknife" apontam para uma importante diversidade de espécies associadas a ambientes úmidos existentes na Cadeia do Espinhaço. Deve-se considerar que a diferença indicada neste estudo relaciona-se principalmente à grande abrangência geográfica, bem como à heterogeneidade dos ambientes amostrados.

As áreas amostradas na Cadeia do Espinhaço mostraram-se bastante distintas em relação à composição florística, sendo verificadas comunidades vegetais que refletem as diferentes peculiaridades de cada ambiente amostrado. Grande parte das plantas associadas a ambientes úmidos é citada como de ampla distribuição fitogeográfica (Sculthorpe 1967, Esteves 1998, Irgang \& Gastal Jr. 1996, Pott \& Pott 2000). Alguns aspectos relacionados a essa expansão podem ser atribuídos a uma menor variação de temperatura e dos fatores edáficos encontrados nos ambientes aquáticos, além do fato de um grande número de espécies apresentarem disseminação de sementes e propágulos vegetativos por pássaros (Sculthorpe 1967).

No entanto, espécies dominantes ou abundantes podem representar apenas uma pequena fração do total da riqueza em muitas comunidades, as raras ou incomuns, por sua vez, podem desempenhar importante papel na preservação da sua integridade (Capers 2000). Por essa razão, para a manutenção da biodiversidade é necessário considerar os fatores que controlam os ecossistemas, sobretudo naqueles onde existem espécies raras (Zedler 1997). No presente estudo, por exemplo, algumas espécies raras foram encontradas nos Rios Corrento, Preto e na Lagoa Nascentes do Taboão. Os trechos estudados dos Rios Corrento e Preto constituem Unidades de Conservação, entretanto a Lagoa Nascentes do Taboão é ainda uma área que carece de proteção.

Os levantamentos da diversidade florística e a análise dos padrões de distribuição das espécies oferecem importantes subsídios para o estabelecimento de prioridades de conservação das comunidades vegetais e das espécies (Bini et al. 2001). Dessa forma, tornase fundamental o incremento de estudos de padrões de distribuição mais completos e que abordem aspectos ecológicos e da dinâmica das espécies que integram os ecossistemas úmidos, sobretudo aqueles mais ameaçados.

Agradecimentos - Ao Fundo Nacional do Meio Ambiente (FNMA) pelo apoio financeiro. Aos colegas do Setor de Recursos da Terra/Cetec pelo apoio logístico. A Edna Bueno pela confecção do mapa. Aos especialistas: Alexandre Salino, André Bragança Gil, Aristônio Magalhães Telles, Cláudia Bove, Paulo Takeo Sano, Pedro Viana Lage, Rubens Mota, Rosana Romero e Jimi Nakajima que contribuíram para as identificações taxonômicas. 


\section{Referências bibliográficas}

APG II. 2003. An update of the Angiosperm Phylogeny Group classification for the orders and families of flowering plants: APG II. Botanical Journal of the Linnean Society 14:399-436.

BACCHI, O., LEITÃO FILHO, H. DE F. \& ARANHA, C. 1984. Plantas invasoras de cultura. Campinas, Instituto Campineiro de Ensino Agrícola. v.3.

BINI, L.M., THOMAZ, S.M. \& SOUZA, D.C. 2001. Species richness and $\beta$ diversity of aquatic macrophytes in the Upper Paraná River floodplain. Archiv für Hydrobiologie 151:511-525.

BRANDÃO, M. LACA-BUENDIA, J.P. \& GAVILLANES, M.L. 1989. Plantas palustres e aquáticas que se comportam como invasoras, no Estado de Minas Gerais. Acta Botanica Brasilica 2:255-266.

BOVE, C.P \& PHILBRICK, C.T. 2006. A new species of Cipoia (Podostemaceae) from Minas Gerais, Brazil. Systematic Botany 31:822-825.

CAPERS, R.S. 2000. A comparison of two sampling techniques in the study of submersed macrophyte richness and abundance. Aquatic Botany 68:87-92.

CETEC - Fundação Centro Tecnológico de Minas Gerais. 1983. Diagnóstico ambiental do Estado de Minas Gerais. Série Publicações Técnicas. Cetec, Belo Horizonte.

COOK, C.D.K. 1996. Aquatic plant book. SPB Academic Publishing, Amsterdam/New York.

COSTA, C.R.N., HERMANN, G., MARTINS, C.S., LINS, L.V. \& LAMAS, I.R. 1998. Biodiversidade em Minas Gerais: um atlas para sua conservação. Fundação Biodiversitas/IEF/SEMAD/CI, Belo Horizonte.

ESPÍNDOLA, E.L.G., BRANCO, M.B.C., FRACÁCIO, R., GUNTZEL, A.M., MORETTO, E.M., PEREIRA, R.H.G., RIETZLER, A.C., ROCHA, O., RODGHER, S., SMITH, W.S. \& TAVARES, K.S. 2003. Organismos aquáticos. In Fragmentação de ecossistemas (D.M. Rambaldi \& D.A.S. Oliveira, org.). Ministério do Meio Ambiente, Brasília, p.201-238.

ESPÍNOLA,L.A. \& FERREIRA, J.J.H. 2007. Espécies invasoras: conceitos, modelos e atributos. Interciência 32:580-585.

FROMM-TRINTA, E. 1996. Flora da Serra do Cipó, Minas Gerais: Lentibulariaceae. Boletim de Botânica da Universidade de São Paulo 15:105-18.

GOUDET, J. 2002. FSTAT - Version 2.9.3.2 for windows: a computer program to calculate F-statistics. http://www. unil.ch/izea/software/fstat.html (accessed 2005 Mar 31).

HASLAM, S.M. 1978. River plants. University Press, Cambridge.

HELTSHE, J.F. \& FORRESTER, N.E. 1983. Estimating species richness using the jackknife procedure. Biometrics 39:1-11.

HENRIQUES, R.P.B., ARAÚJO, D.S.D., ESTEVES, F.A. \& FRANCO, A.C. 1988. Análise preliminar das comunidades de macrófitas aquáticas da Lagoa Cabiúnas, Rio de Janeiro, Brasil. Acta Limnológica Brasileira 2:783-802.
HOEHNE, F.C. 1979. Plantas aquáticas. Instituto de Botânica, São Paulo.

IBGE - Instituto Brasileiro de Geografia e Estatística. 1977. Carta do Brasil. IBGE, Secretaria do Planejamento e Coordenação Geral/Instituto de Geociências aplicadas de Belo Horizonte, Belo Horizonte.

IRGANG, B.E. \& GASTAL JUNIOR, C.V.S. 1996. Macrófitas aquáticas da planície costeira do RS. CPG-Botânica/ UFRGS, Porto Alegre.

JOLY, A.B. 1970. Conheça a vegetação brasileira. Editora da Universidade de São Paulo. Editora Polígono, São Paulo.

LEITÃO FILHO, H.F. BACCHI, O. \& ARANHA, C. 1972. Plantas invasoras de culturas no Estado de São Paulo. Hucitec, São Paulo, v.1.

LEITÃO FILHO, H. DE F., ARANHA, C. \& BACCHI, O. 1975. Plantas invasoras de culturas no Estado de São Paulo. Hucitec, São Paulo, v.2.

LONGHI-WAGNER, H.M, BITTRICH, V., WANDERLEY, M.G.L. \& SHEPHERD, G.J. 2001. Poaceae. In Flora Fanerogâmica do Estado de São Paulo. (M.G.L. Wanderley, G.J. Shepherd \& A.M. Giulietti, coord.). Fapesp/Hucitec, São Paulo, v.1.

LORENZI, H. 2000. Plantas daninhas do Brasil: terrestres, aquáticas, parasitas e tóxicas. $3^{\text {a }}$ ed. Instituto Plantarum, Nova Odessa.

MAGURRAN, A.E. 1988. Ecological diversity and its measurement. Croom Helm, London.

MATIAS, L.Q., AMADO, E.R. \& NUNES, E.P. 2003. Macrófitas aquáticas da lagoa de Jijoca de Jericoacoara, Ceará, Brasil. Acta Botanica Brasilica 17: 623-631.

MENDONÇA, M.P.E. \& LINS, L.V. 2000. Lista vermelha das espécies ameaçadas de extinção da flora de Minas Gerais. Fundação Biodiversitas/Fundação Zoobotânica de Belo Horizonte, Belo Horizonte.

MÜLLER-DOMBOIS, D. \& ELENBERG, H. 1974. Aims and methods for vegetation ecology. J. Wiley e Sons, New York.

NESOM, G.L. 1994. Inulopsis synopsis (Asteraceae: Astereae). Phytologia 76:115-124.

NIMER, E. 1977. Clima: Região Sudeste. Geografia do Brasil. IBGE, Rio de Janeiro.

PEDRALLI, G. \& GONÇALVES, A.P.S. 1997. Levantamento florístico e aspectos da sucessão em duas lagoas na região cárstica de Minas Gerais, Brasil. Daphne 7:17-25.

PEDRALLI, G. \& MEYER, S.T. 1996. Levantamento da vegetação aquática ('macrófitas") e das florestas de galeria na área da Usina Hidrelétrica de Nova Ponte, Minas Gerais. Bios 4:49-60.

PEDRALLI, G., STEHMANN, J.R, TEIXEIRA, M.C.B, OLIVEIRA, V.L. \& MEYER, S.T. 1993a. Levantamento da vegetação aquática ("macrófitos") na EPDAPeti, Santa Bárbara, MG. Iheringia, Serie Botânica, 43:15-28. 
PEDRALLI, G., MEYER, S.T., TEIXEIRA, M.C.B., \& STEHMANN, J.R. 1993b. Levantamento dos macrófitos aquáticos e da mata ciliar do reservatório de Volta Grande, Minas Gerais, Brasil. Iheringia, Serie Botânica, 43:29-40.

PHILBRICK, C.T, NOVELO, A. \& IRGANG, B.E. 2004. Two new genera of Podostemaceae from the state of Minas Gerais, Brazil. Systematic Botany 29:109-117.

POLLOCK, M.M, NAIMAN, R.J. \& HANLEY, T.A. 1998. Plant species richness in riparian wetlands - A test of biodiversity theory. Ecology 79:94-105.

POTT, V.J. \& POTT, A. 2000. Plantas aquáticas do Pantanal. Embrapa, Brasília.

RIBEIRO, J.F. \& WALTER, B.M.T. 1998. Fitofisionomias do bioma Cerrado. In Cerrado: ambiente e flora. (S.M. Sano \& S.P. Almeida, ed.). EMBRAPA-CPAC, Planaltina.

RIZZINI, C.T. 1997. Tratado de fitogeografia do Brasil: aspectos ecológicos, sociológicos e florísticos. $2^{\underline{a}}$ ed. Âmbito Cultural, Rio de Janeiro.
SCREMIN-DIAS, E. 2000. A plasticidade fenotípica das macrófitas aquáticas em resposta à dinâmica ambiental. In Tópicos Atuais em Botânica (T. Cavalcante \& B.M.T. Walter, orgs.). Sociedade Botânica do Brasil/Embrapa, Brasília, p.189-194.

SCREMIN-DIAS, E., POTT, V.J., HORA, R.C. \& SOUZA, P.R. 1999. Nos jardins submersos da Bodoquena. Editora UFMS, Mato Grosso do Sul.

SCULTHORPE, C.D. 1967. The biology of aquatic vascular plants. St. Martins Press, New York.

THOMAZ, S.M. \& BINI, L.M. 2003. Análise crítica dos estudos sobre macrófitas aquáticas desenvolvidos no Brasil. In Ecologia e manejo de macrófitas aquáticas (S.M. Thomaz \& L.M. Bini, ed.). EDUEM, Maringá, p.19-38.

ZEDLER, J.B. 1997. Restaurar a diversidade em pântanos salgados: podemos faze-lo? In Biodiversidade. (E.O. Wilson), Nova Fronteira, Rio de Janeiro, p. 407-418. 
